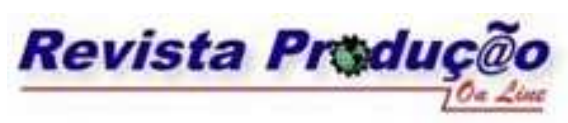

\title{
MUDANÇA ORGANIZACIONAL E FATORES CRÍTICOS DE SUCESSO: ESTUDO DE CASO NO SISTEMA FIERGS
}

\section{ORGANIZATIONAL CHANCE AND CRITICAL SUCCESS FACTORS: CASE STUDY IN THE SISTEMA FIERGS}

\author{
Andressa Lacerda Capelli \\ UFRGS/ PPGEP, Mestre em Engenharia de Produção, Pesquisadora \\ andressacapelli@hotmail.com \\ Fernando Gonçalves Amaral \\ UFRGS/ PPGEP, Doutor, Professor \\ amaral@producao.ufrgs.br
}

\begin{abstract}
RESUMO
A mudança organizacional (MO) é uma iniciativa realizada por empresas que buscam adequar sua atuação em conformidade com a demanda do mercado, porém estudos apontam alto índice de insucessos e desistências, dada a complexidade da iniciativa. Alcançar os resultados propostos em uma MO depende de alguns fatores, dentre estes, sistemáticas de apoio para o desenvolvimento da iniciativa e a gestão dos fatores críticos de sucesso (FCS). A complexidade da MO agrava-se em entidades caracterizadas por interferências políticas na sua atuação, trocas periódicas de mandato, complexidade na mensuração de ganhos em produtos e serviços. O objetivo deste estudo é estruturar e propor uma sistemática de apoio para MO para federações de indústrias, buscando a contribuição positiva dos fatores críticos de sucesso. A metodologia empregada foi a de estudo de caso. Os resultados alcançados provêm da estruturação e compreensão de MO através dos serviços compartilhados do Programa de Transformação do Sistema FIERGS, com o levantamento, identificação e registro das ações realizadas de $\mathrm{MO}$ e a descrição, análise e comparação das sistemáticas de apoio e FCS.
\end{abstract}

Palavras-chave: mudança organizacional; sistemática de apoio; fatores críticos de sucesso; Federação de Indústrias. 


\begin{abstract}
The organizational change (OC) is an initiative undertaken by companies that seek matching its performance in accordance with market demand, but studies show high rate of dropouts and failures, given the complexity of the initiative. Achieving the results proposed in $\mathrm{OC}$ is dependent on systematic support for the development and management of critical success factors (CSF). The complexity of the $\mathrm{OC}$ is deteriorating in entities characterized by political interference in its operation, periodic exchanges of mandate, complexity in the measurement of gains in services. This study proposes a structure and systematic support for OC to federations of industries, looking for the positive contribution of the CSF. The methodology employed was the case study. The results come from the structuring and understanding through the Transformation Program of Sistema FIERGS through the survey, identification and registration of the shares held in OC, description, analysis and comparison of systematic support and FCS.
\end{abstract}

Keywords: organizational change; systematic support; critical factors of success; Industry Federation.

\title{
1 INTRODUÇÃO
}

As organizações caracterizavam-se pela utilização de um processo fabril de baixa escala de produção, imerso em um ambiente bastante estável. A vida pacata destas organizações foi perturbada pela chegada de inovações que trouxeram agilidade e informação, permitindo ampliar o comércio entre localidades (LIMA, 2003), sendo o começo de uma série de modernizações sucessivas que as organizações avaliariam a utilização de recursos, processos produtivos e ampliação da oferta dos produtos, em escala geométrica e transformando mercados locais em mercados mundiais.

A "mudança é um processo consciente de se criar uma nova realidade organizacional" (MOTTA, 1998, p. 46), independente do tipo de entidade que esteja submetendo-se, o processo da mudança é diferente devido ao seu mercado de atuação, estratégia de atuação, composição societária e modelo de gestão, entre outros. A mudança organizacional (MO) em uma entidade do tipo Federação de Indústrias torna-se desafiadora pelo caráter político da entidade, que atende demandas das indústrias que representa frente a decisões puramente técnicas ou administrativas. $\mathrm{O}$ tipo de modelo de gestão de federações de indústria caracteriza-se como presidencial, com mandatos de três anos e uma reeleição, fator que contribui para a complexidade da mudança organizacional.

Para desenvolver uma mudança organizacional é importante utilizar sistemáticas de apoio que objetivem auxiliar o desenvolvimento das propostas, de forma estruturada, para poder alinhar ações e priorizar atividades, possibilitando assim o alcance dos resultados esperados. No entanto, somente a simples utilização de uma sistemática de apoio não garante o alcance dos resultados esperados, pois existem fatores críticos de sucesso (FCS) que interferem diretamente no desenvolvimento desta 
iniciativa.

Segundo Gonçalves (2000), a entidade que realizar uma MO obterá ganhos bastante significativos, proporcionais aos desafios propostos e ao envolvimento da alta administração em concretizá-los. Esses ganhos estão relacionados a resultados em redução de gastos; investimentos em ferramentas para aperfeiçoamento de processos; redução do tempo de realização de atividades; ampliação na atuação da atividade fim. Neste sentido, o objetivo deste estudo é estruturar e propor uma sistemática de apoio, que resulte na maior interferência positiva de FCS em uma MO, para entidades do tipo federação de indústrias. O contexto específico foi estudado, a partir da compreensão de mudança organizacional pelos serviços compartilhados do Programa de Transformação do Sistema FIERGS, levantando, identificando e registrando procedimentos e resultados de mudanças organizacionais realizadas; além de descrever, analisar e comparar as sistemáticas já utilizadas na entidade com base nos FCS resultantes das aplicações.

\section{FUNDAMENTAÇÃO TEÓRICA}

Este estudo fundamentou-se em conceitos de mudança organizacional (MO), sistemáticas de apoio e fatores críticos de sucesso (FCS), utilizados como base teórica na análise do caso prático e na proposição de uma sistemática de apoio.

\subsection{MUDANÇA ORGANIZACIONAL}

As organizações são compostas de um conjunto de atividades com elementos comuns, que permitem o agrupamento de pessoas e atividades (KANTER et al., 1992). A busca por melhores níveis de desempenho é o resultado do processo de descoberta de oportunidades, podendo ser através de uma MO, em que é necessário que a empresa deposite grandes esforços na criação de idéias inovadoras (MANDELLI, 2003), favorecendo atingir o desempenho esperado (AZEVEDO, 1997). Porém, deve-se atentar que o interesse de uma entidade pela MO pode ser decorrente do fator ambiental interno ou externo.

As razões citadas são argumentos para que uma MO possa ocorrer, pois o resultado esperado desse redesenho interno, geralmente, visa a redução de custos e aumento da flexibilidade organizacional, em que quanto maior e mais antiga for a empresa, mais lentos poderão ser os mecanismos de crescimento (KANTER et al., 1992). Portanto, uma organização com perspectivas e visão de futuro deve estar voltada aos clientes, à qualidade dos produtos e serviços oferecidos e à sociedade.

Neste trabalho, mudança organizacional (MO) é entendida como a definição dada por Lima (2003), sendo qualquer alteração, planejada ou não, nos componentes organizacionais: pessoas, trabalho, estrutura formal, cultura, ou relações entre organização e seu ambiente - que gerem consequiências relevantes de natureza positiva ou negativa, para a eficiência, eficácia e sustentabilidade organizacional proposto.

A dificuldade de realizar uma MO está contida na "compreensão mais simples de um problema e sua solução, associada à noção de urgência em instituir um método mais simples, rapidamente poder fornecer a inovação pela qual tanta empresa anseia" (AZEVEDO, 1997, p. 38). Assim, 
comete-se o erro de ignorar a inexistência de soluções ou sistemáticas prontas para serem utilizadas, (sendo cada caso, um caso) essas devem ser adequadas conforme as necessidades da empresa, antes de serem colocadas em prática.

\subsection{SISTEMÁTICAS DE MO}

O principal objetivo de uma empresa em utilizar uma sistemática de MO é auxiliar no desenvolvimento das propostas, de forma estruturada, alinhando as ações que se inter-relacionam através da priorização de atividades frente às demais, possibilitando à empresa o alcance do novo modelo de atuação. Porém, o simples fato de utilizar uma determinada sistemática de apoio à MO utilizada por outra empresa, não garante o alcance de todos os resultados esperados, pois existem fatores que interferem diretamente no desenvolvimento desta iniciativa; assim, uma mesma sistemática gera resultados diferentes quando aplicada em diferentes realidades organizacionais. Da totalidade, $70 \%$ dos casos de MO são considerados fracassados (conforme dois estudos, publicados por Arthur D. Little e McKinsey \& Co) que centenas de MOs estudadas acabavam sendo suspensas por deixarem de produzir os resultados esperados, apontando, assim, um alto índice de fracasso (SENGE, 2000).

Dentre a literatura pesquisada, identificaram-se quatro principais sistemáticas de apoio à MO. A sistemática proposta por Kettinger (1997) apud Torres (2002) é caracterizada pelas etapas: visualizar, iniciar, diagnosticar, redesenhar, reconstruir e avaliar, sendo cada etapa composta por atividades para desenvolvimento. Já a sistemática desenvolvida por Rodrigues e Nakayama (2000) é composta pelas etapas: identificação e seleção dos processos, identificação dos instrumentos de mudança, desenvolvimento de visão de atividades e dos objetivos do processo, entendimento e medição dos processos existentes, planejamento e construção de um novo processo.

A terceira sistemática (LORANGE et al., 1994) está estruturada em dois grupos de atividades (primárias condicionantes e mecanismos secundários), sendo que em cada um dos grupos há atividades de: avaliação ambiental, condução da mudança, conexão estratégica e mudança operacional, recursos humanos como recursos e responsabilidades, coerência. A quarta sistemática proposta, Kotter (1995), caracteriza-se em quatro fases ilustradas na Figura 1, seguido do plano de implementação.

As quatro sistemáticas de apoio descritas servem para auxiliar no processo de $\mathrm{MO}$, para que a empresa que realiza esta iniciativa tenha mais chances de chegar ao fim desse processo alcançando o modelo de gestão pretendido. Conhecer os pontos frágeis da entidade e escolher a sistemática adequada para utilizar no processo, demonstra interesse pela busca consistente de alterar o atual modelo de gestão, dado que uma MO não funciona como deveria, pois dentre mil empresas que realizam esta iniciativa, menos de $50 \%$ atingem resultados de sucesso, devido à ameaça deste processo ao equilíbrio fictício da organização (SENGE, 2000). Ressalta-se então a necessidade de identificar os pontos críticos da organização, por isso definir um problema é um processo complexo e conflituoso, pois questiona concepções e percepções individuais sobre a realidade organizacional (MOTTA, 1998). 


\section{Revista Produç@̃}

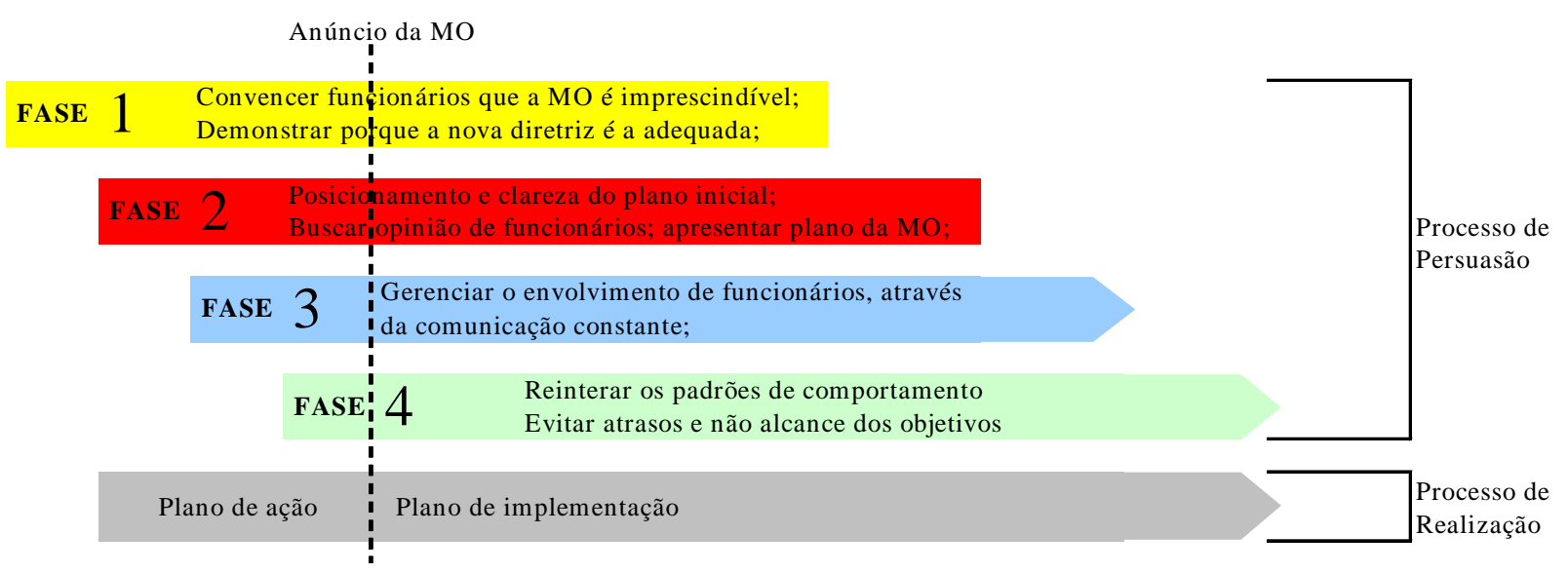

Figura 1 - Sistemática de MO proposta por John P. Kotter (1995).

Fonte: adaptado de KOTTER, 1995.

\subsection{FATORES CRÍTICOS DE SUCESSO EM MUDANÇA ORGANIZACIONAL}

Os fatores críticos de sucesso (FCS) são os pontos-chave que definem o sucesso ou o fracasso de uma MO, sendo tomados como condições fundamentais a serem cumpridas para que a instituição sobreviva e tenha sucesso no seu mercado de atuação. A literatura permitiu observar sete FCS como sendo os de maior relevância para uma MO, tais como: gestão ativa e dedicada; objetivos e metas clarificados; acompanhamento freqüente; disponibilização de recursos em quantidade e qualidade adequados; alocação bem definida dos papéis e responsabilidades; comunicação constante e eficiente; mudança cultural. Estes FCS são descritos na Quadro 1.

Desta forma, evidencia-se a necessidade de preparar a instituição para realizar uma MO. Segundo Motta (1998), como qualquer outra decisão empresarial, a mudança exige intenção, cooperação e apoio. Logo, sua eficácia depende de todo o potencial e expectativa dos funcionários e será mais permanente e efetiva à medida que houver o envolvimento de todos.

\begin{tabular}{|c|l|}
\hline FCS & \multicolumn{1}{c|}{ Descrição } \\
\hline $\begin{array}{c}\text { Gestão ativa e } \\
\text { dedicada }\end{array}$ & $\begin{array}{l}\text { É a interação com as propostas, dedicando-se à solução de problemas, através da articulação, } \\
\text { sensibilização, detalhamento de informações, identificação de problemas futuros, interferindo } \\
\text { quando conveniente e antecipando acontecimentos fatídicos que geram desgaste do processo, } \\
\text { através de um grupo que realize a gestão dos assuntos estratégicos (MOTTA, 1998). }\end{array}$ \\
\hline $\begin{array}{c}\text { Ação a ser empreendida e direcionada a um responsável, sendo necessário um tratamento inicial } \\
\text { que permita agrupar idéias complementares e ordená-las em uma seqüência de execução } \\
\text { clarificados metas }\end{array}$ & $\begin{array}{l}\text { MANDELLI, 2003), sendo assim, fundamental a participação do maior número de } \\
\text { representantes na estruturação da proposta de plano de ação, objetivando "uma análise racional, } \\
\text { participativa e negociada entre os envolvidos com o problema a fim de alterar uma situação } \\
\text { organizacional específica", sendo validado pela alta administração da entidade (MOTTA, 1998, } \\
\text { p. 134). Esse agrupamento de idéias deve ser conciso e de domínio comum dentro da empresa, } \\
\text { para que todos trabalhem num mesmo sentido. }\end{array}$ \\
\hline Ecompanhamento & É monitorar problemas (MOTTA, 1998) e acompanhar o progresso das ações e resultados \\
\hline
\end{tabular}




\begin{tabular}{|c|c|}
\hline freqüente & $\begin{array}{l}\text { gerados (OBOLENSKY, 1994), ressaltando que saber o que monitorar é imprescindível, pois } \\
\text { agrega informações para uma tomada de decisão, caso a MO não esteja atingindo os objetivos } \\
\text { propostos, no prazo estabelecido. Para tanto, monitorar o tempo é insuficiente, pois ter a } \\
\text { informação que o projeto está atrasado sem saber as razões deste atraso não auxilia nenhum tipo } \\
\text { de melhoria no ponto crítico da atividade (KERZNER, 2002). Para acompanhar o } \\
\text { desenvolvimento de uma MO é sugerida a utilização de indicadores de desempenho, } \\
\text { acompanhando a evolução das alterações e se estão alcaçando os resultados propostos. }\end{array}$ \\
\hline $\begin{array}{l}\text { Disponibilização } \\
\text { de recursos em } \\
\text { quantidade e } \\
\text { qualidade } \\
\text { adequados }\end{array}$ & $\begin{array}{l}\text { É planejar e administrar os recursos investidos na MO, pois a empresa precisará ter fôlego } \\
\text { financeiro para investir no processo, sendo importante que os recursos sejam planejados e } \\
\text { administrados, dado que os resultados se dão no médio e longo prazos e o processo não seja } \\
\text { interrompido por falta de recursos. }\end{array}$ \\
\hline \multirow{3}{*}{$\begin{array}{l}\text { Alocação bem } \\
\text { definida dos } \\
\text { papéis e } \\
\text { responsabilidades }\end{array}$} & $\begin{array}{l}\text { O bom funcionamento da estrutura organizacional necessita da definição de papéis e } \\
\text { responsabilidades, clarificando a ordem hierárquica que as decisões devem seguir. A ausência } \\
\text { destas responsabilidades formalizadas pode gerar problemas quanto à procedência de } \\
\text { informações, tomada de decisões no âmbito hierárquico inferior e mais de uma definição sobre } \\
\text { um mesmo assunto (MANDELLI, 2003). }\end{array}$ \\
\hline & $\begin{array}{l}\text { Obolensky (1994) acrescenta que deve existir uma equipe de transição e esta ter autoridade e } \\
\text { influência para agir e decidir sobre situações conflitantes, desempenhando as seguintes funções: } \\
\text { monitorar e relatar a evolução das ações; fornecer suporte e orientar o desenvolvimento e a } \\
\text { implementação do plano de ação; gerar relatórios à alta direção; identificar o canal de } \\
\text { comunicação interno e externo; gerir projetos e suporte a sistemas; atualizar planos e resultados; } \\
\text { agir como solucionador de crises. }\end{array}$ \\
\hline & $\begin{array}{l}\text { Para Azevedo (1997), é necessário consenso na necessidade de mudar, em todos os níveis da } \\
\text { organização, e um elemento-chave é a comunhão entre o topo da administração e a equipe da } \\
\text { MO: ambos devem concordar quanto ao escopo previsto e os resultados esperados. }\end{array}$ \\
\hline $\begin{array}{l}\text { Comunicação } \\
\text { Constante e } \\
\text { Eficiente }\end{array}$ & $\begin{array}{l}\text { É buscar as "comunicações abertas e francas através de canais formais e informais que facilitam } \\
\text { o desenvolvimento do consenso" (AZEVEDO, 1997, p. 33). Para a integração dos funcionários á } \\
\text { iniciativa é necessária a comunicação permanente (AZEVEDO, 1997), divulgando informações } \\
\text { oficiais e combatendo as fontes informais. Considera-se que quanto menor for o tempo } \\
\text { delimitado, mais eficiente o plano de comunicação deve ser, visando alcançar o resultado } \\
\text { desejado. As dúvidas mais comuns sobre objetivos e resultados esperados de uma MO estão } \\
\text { relacionadas ao que é comunicado ou como que são passadas as informações. Ao realizar uma } \\
\text { ação de comunicação é importante comunicar somente fatos, não valores e fazê-lo pessoalmente, } \\
\text { deixando os artifícios estáticos, vídeos, publicações ou grandes eventos (LARKIN; LARKIN, } \\
\text { 1996). }\end{array}$ \\
\hline \multirow{3}{*}{ Mudança cultural } & $\begin{array}{l}\text { Cultura organizacional é um conjunto de valores, crenças e hábitos coletivamente } \\
\text { compartilhados, que juntos tipificam cada organização e a singularizam perante outras } \\
\text { (MOTTA, 1998). Dado isto, o desconforto gerado pela MO, segundo Garvin e Roberto (2005), é } \\
\text { resultante da relutância dos funcionários em alterar seus hábitos, pois crêem que o método que } \\
\text { funcionava no passado é bom o suficiente para continuar sendo utilizado. }\end{array}$ \\
\hline & $\begin{array}{l}\text { Um fator agravante deste FCS é a constante alteração na liderança da entidade, proveniente de } \\
\text { sucessões da alta administração, característica do tipo de organização de Federações de } \\
\text { Indústrias. Alterações na alta administração resultam numa resistência ainda maior, pois a } \\
\text { sequiência de desapontamentos e desconfiança com as gestões anteriores cria um ambiente } \\
\text { negativo em relação à próxima gestão (GARVIN; ROBERTO, 2005). }\end{array}$ \\
\hline & A certeza é que esta não é uma tarefa fácil ou de curto prazo, e que os indivíduos envolvidos na \\
\hline
\end{tabular}




\begin{tabular}{|l|l|}
\hline & $\begin{array}{l}\text { organização estão focados nos objetivos e desempenho específicos, tendendo a preservar as } \\
\text { rotinas, tornando-se dependentes e condicionados a repeti-la. A maior dificuldade acaba sendo a } \\
\text { de romper com o estabelecido, pelo receio de perder as bases de seu sucesso (MOTTA, 1998). }\end{array}$ \\
\hline
\end{tabular}

\section{PROCEDIMENTOS METODOLÓGICOS}

Quadro 1 - Descrição dos FCS.

Os procedimentos metodológicos possibilitaram a estruturação e proposição de uma sistemática de apoio para MO em entidades do tipo federações de indústrias, respeitando suas características e buscando a contribuição positiva dos fatores críticos de sucesso. Neste contexto, foi aplicado o método de Estudo de Caso (YIN, 1994). Neste trabalho, o processo de coleta pode ser considerado como observação participante, em que o observador deixou de ser um membro passivo e pode assumir vários papéis, participar e influenciar os eventos em estudo (YIN, 1994). Para o estudo de caso, a observação participante foi realizada pelo analista do escritório do Programa de Transformação do Sistema FIERGS (EPT), desde o início da MO em julho/ 2005, até seu término em agosto/ 2008. A figura 2 ilustra as etapas que se sucederam na realização da pesquisa.

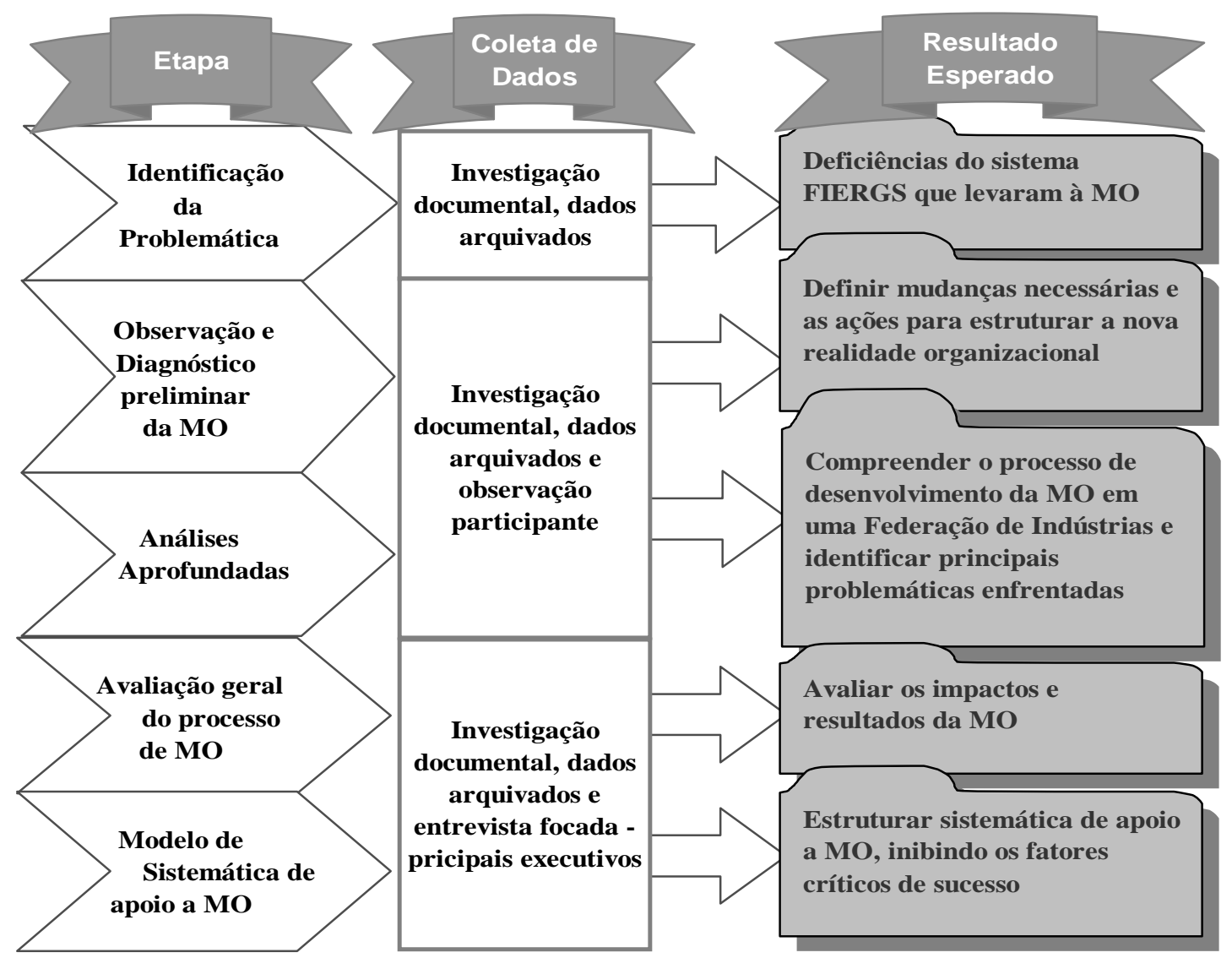

Figura 2 - Etapas do método empregado na estruturação da sistemática de apoio à MO. 
A identificação da problemática consistiu no primeiro passo para conhecer e, posteriormente, estruturar um modelo de sistemática de apoio à MO. Assim, foi possível compreender as principais razões que a alta administração calcou-se na decisão de realizar a MO. Nesta etapa preliminar, os dados foram coletados através de relatórios de consultorias em que fornecem informações relativas à estrutura organizacional anterior à realização de qualquer tipo de mudança organizacional.

A observação e o diagnóstico preliminar consistiram na compreensão das propostas de alteração do atual modelo de gestão e governança, que incluiu o entendimento da elaboração e aprovação das alternativas para as áreas de serviços compartilhados, estruturando um novo modelo de atuação. Juntamente, foi descrita a sistemática de apoio utilizada pela consultoria externa à entidade, que induziu a estruturação do novo modelo. Esta etapa se valeu de documentos de consultoria e da observação participante, que forneceram dados sobre o método de trabalho, propostas de mudança estruturadas para o novo modelo.

As análises aprofundadas foram constituídas da descrição do processo de implementação das alterações sugeridas para os serviços compartilhados, registrando os acontecimentos que se sucederam na implementação das propostas, considerando os atores envolvidos e os resultados alcançados, verificando aquelas que foram implementadas com efetividade. Esta etapa também se valeu da observação participante do analista do EPT e da análise de documentos de consultoria, de relatórios de acompanhamento do desenvolvimento à alta direção, contendo informações referentes: à situação de implementação das propostas da MO; às alterações das propostas do novo modelo e às frentes de trabalho constituídas para o desenvolvimento desta iniciativa. Ainda, foram verificados os resultados gerados na implementação das mudanças, considerando as alterações propostas e as efetivamente realizadas, sendo possível compreender, por meio das principais dificuldades enfrentadas, a complexidade que envolveu a mudança organizacional.

A avaliação geral do processo de mudança organizacional consistiu no balanço final de sua realização, pontuando os ganhos obtidos e as dificuldades enfrentadas, analisando a relação direta entre as sistemáticas de apoio utilizadas e a interferência dos fatores críticos de sucesso, através de uma matriz de inter-relacionamento (Quadro 2). A etapa utilizou-se dos documentos de consultoria; observação participante; entrevista focada com o representante da alta administração, o Presidente da entidade. A partir de tópicos extraídos do estudo de caso observado, foi realizada uma entrevista com o Presidente do Sistema FIERGS, considerado como representante da alta administração e idealizador da MO. A entrevista utilizou-se dos questionamentos (Quadro 3).

\begin{tabular}{|c|c|c|c|}
\hline FCS & Sistemática A & Sistemática Z (Consultoria Z) & Sistemática Z (EPT) \\
\hline Gestão ativa e dedicada & Negativo & Positivo & Negativo \\
\hline Objetivos e metas clarificados & Negativo & Positivo & Negativo \\
\hline Acompanhamento freqüente & Positivo & Positivo & Positivo \\
\hline $\begin{array}{c}\text { Disponibilização de recursos em } \\
\text { quantidade e qualidade adequados }\end{array}$ & Negativo & Positivo & Positivo \\
\hline $\begin{array}{c}\text { Alocação bem definida de papéis e } \\
\text { responsabilidades }\end{array}$ & Negativo & Positivo & Positivo \\
\hline
\end{tabular}




\begin{tabular}{|c|c|c|c|}
\hline Comunicação constante e eficiente & Negativo & Indiferente & Negativo \\
\hline Mudança cultural & Negativo & Negativo & Negativo \\
\hline
\end{tabular}

Quadro 2 - Proposta de matriz de inter-relação entre Sistemáticas A e Z e FCS.

\begin{tabular}{|c|l|}
\hline Ordem & \multicolumn{1}{|c|}{ Questionamento } \\
\hline $1^{\text {a }}$ & Quais os principais aspectos referentes ao Sistema FIERGS que o levaram à decisão de realizar uma MO. \\
\hline $2^{\text {a }}$ & Quais os principais ganhos organizacionais do Sistema FIERGS, obtidos com a MO. \\
\hline $3^{\text {a }}$ & Quais são as principais dificuldades enfrentadas na utilização das Sistemáticas de apoio A e Z. \\
\hline $4^{\text {a }}$ & Priorizar os sete FCS, definidos neste trabalho, em ordem crescente de importância e comentá-los. \\
\hline $5^{\text {a }}$ & $\begin{array}{l}\text { Analisar e validar a matriz de inter-relação (Figura 8) entre as sistemáticas utilizadas e os FCS resultantes } \\
\text { das aplicações, verificando os impactos indicados: positivo; indiferente; negativo. Comente-os. }\end{array}$ \\
\hline $6^{\text {a }}$ & O caso de MO no Sistema FIERGS é considerado de sucesso? Comente. \\
\hline
\end{tabular}

Quadro 3 - Proposta de matriz de inter-relação entre Sistemáticas A e Z e FCS.

A estruturação da proposta de sistemática de apoio à MO para entidades de classe, como uma Federação de Indústria tomou-se como base as sugestões provenientes da entrevista focada, melhores práticas identificadas no estudo de caso e referencial teórico. Esta proposta de sistemática foi estruturada buscando a contribuição positiva dos fatores críticos de sucesso para MO em Federação de Indústrias. Este se propôs a auxiliar casos semelhantes ou mesmo estruturas organizacionais similares. A partir da metodologia proposta estruturada foi realizada a aplicação da mesma no Programa de Transformação do Sistema FIERGS.

\section{RESULTADOS}

A FIERGS tem 108 sindicatos filiados e o CIERGS, mais de dois mil associados. E, juntas, representam as quarenta e um mil fábricas em atividade no Estado, que empregam diretamente seiscentas mil pessoas. O Sistema FIERGS é a entidade que direciona e alinha as demais entidades que o compõem (SESI, SENAI, CIERGS e IEL), estando voltado à promoção da competitividade da Indústria gaúcha, na liderança da criação de um ambiente favorável aos negócios, bem como no estímulo do desenvolvimento humano e tecnológico.

\subsection{IDENTIFICAÇÃO DA PROBLEMÁTICA}

A aplicação da metodologia proposta foi realizada no Sistema FIERGS por meio do acompanhamento do processo de melhoria dos modelos de gestão e de governança, iniciado em 2005, a partir da posse da nova gestão da Entidade. A primeira ação do Presidente foi a contratação de uma empresa de consultoria especializada (doravante denominada de Consultoria Z), para realizar o diagnóstico dos modelos de gestão e de governança, sendo este dividido em três enfoques: defesa de interesses e representações; modelo organizacional e de gestão; modelo de governança. Neste estudo, somente foi abordado o enfoque de serviços compartilhados do modelo organizacional e de gestão. 
No modelo organizacional e de gestão da entidade, analisado pela Consultoria Z, verificou-se o funcionamento da estrutura organizacional da instituição, ressaltando: consolidação da integração das áreas compartilhadas; fortalecimento da organização da área técnica; melhorias em processos e ferramentas; fortalecimento e/ ou criação de novas áreas e ajustes em linhas de reporte. Este estudo detalhada o primeiro aspecto (Quadro 4).

A demanda da MO seria a integração das áreas compartilhadas, gerando benefícios como a otimização e automação de processos, tornando-os mais eficientes e eficazes; ganhos de escala em compras unificadas, administração de bens; terceirização de atividades pouco críticas.

\begin{tabular}{|l|l|}
\hline \multicolumn{1}{|c|}{ Deficiências } & \multicolumn{1}{c|}{ Justificativas } \\
\hline $\begin{array}{l}\text { Processo de integração das } \\
\text { áreas meio não está } \\
\text { finalizado }\end{array}$ & $\begin{array}{l}\text { Implementação da área de Serviços Compartilhados encontra-se em transição do } \\
\text { estágio de “Junção de Recursos" para o de "Consolidação Organizacional”, figura 21, } \\
\text { que resulta num grande número de funcionários realizando tarefas administrativas. }\end{array}$ \\
\hline $\begin{array}{l}\text { Necessidade de } \\
\text { padronização de melhores } \\
\text { práticas dentro das áreas } \\
\text { meio }\end{array}$ & $\begin{array}{l}\text { Oportunidade de aumento de produtividade através da centralização completa das } \\
\text { atividades administrativas, que atualmente são realizadas de forma dispersa. }\end{array}$ \\
\hline
\end{tabular}

Quadro 4 - Problemáticas identificadas para modelo organizacional e de gestão - consolidação da integração das áreas compartilhadas.

Fonte: Adaptado de $1^{\circ}$ relatório Consultoria Z (2005).

\subsection{OBSERVAÇÃO E DIAGNÓSTICO PRELIMINAR DA MUDANÇA ORGANIZACIONAL}

A observação e o diagnóstico do modelo organizacional e de gestão foram realizados para a posterior proposição de alternativas, que constituem o novo modelo para a entidade. A sistemática que foi utilizada pela Consultoria $\mathrm{Z}$ para estruturar o novo modelo é composta por cinco itens (Figura 3).

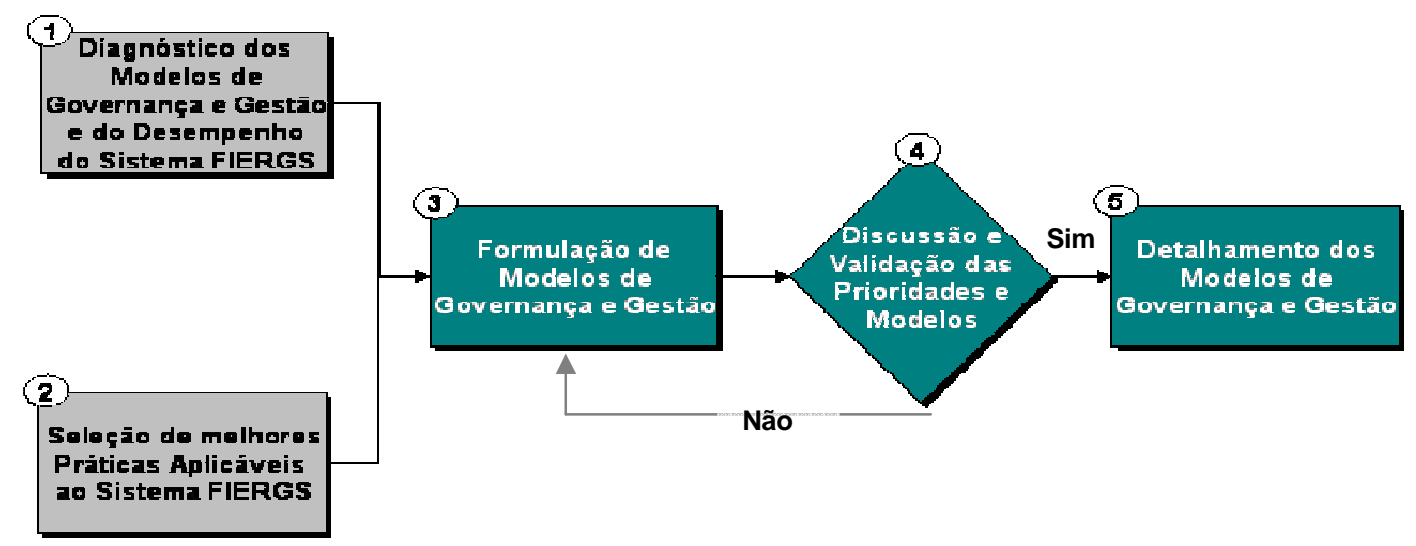

Figura 3 - Sistemática utilizada pela Consultoria Z

Fonte: Adaptado de Consultoria Z (2005). 
O diagnóstico dos modelos de governança e gestão e do desempenho do Sistema FIERGS foi realizado para avaliar o desempenho financeiro, operacional e de gestão da entidade; mapear a estrutura organizacional. Neste primeiro item foram entrevistados quarenta funcionários e identificaram-se oportunidades de melhorias. As oportunidades foram classificadas em níveis de complexidade de realização, considerando o impacto destas nas atividades da entidade. Os níveis variando de baixa (zero) à alta (quatro), sendo consideradas de nível três as oportunidades relacionadas à consolidação da integração da CAF: continuação do processo de integração; padronização de melhores práticas.

A seleção de melhores práticas aplicáveis ao Sistema FIERGS referem-se às entidades que são consideradas de sucesso no Brasil e no exterior. A Consultoria $Z$ visitou, mapeou e analisou as melhores práticas em modelos de Governança e Gestão nas Federações de Indústrias indicadas: FIEB - Bahia; FIESC - Santa Catarina e FIEMG - Minas Gerais.

$\mathrm{Na}$ formulação dos Modelos de Governança e de Gestão foram identificadas e descritas de duas a três alternativas para cada problemática, em nível macro. Para isso, tomou-se como base a estrutura organizacional da entidade em junho de 2005 e foi proposto um novo modelo. Este assegurava a obtenção dos benefícios: consolidação de serviços compartilhados; clareza organizacional; congregação de atividades dispersas; linhas de reporte adequadas.

A discussão e validação das prioridades e modelos constituíram-se na etapa de escolha de uma dentre as alternativas estruturadas pela Consultoria Z, como sendo a mais adequada para a formulação do novo modelo de governança e de gestão, em relação à consolidação da integração das áreas meio (Quadro 5).

Com a aplicação da sistemática da Consultoria Z, estruturou-se o passo a passo da $\mathrm{MO}$ realizada no Sistema FIERGS. Em que cada item, gerando um resultado positivo que foi agregado ao novo modelo de gestão e governança. O detalhamento desse modelo foi essencial para a realização de uma $\mathrm{MO}$, pelo fato de definir a ordem de realização das ações, priorizando assim a seqüência de acontecimentos.

\begin{tabular}{|l|l|}
\hline \multicolumn{1}{|c|}{ Deficiências } & \multicolumn{1}{c|}{ Proposta/ Alternativa Aprovada } \\
\hline $\begin{array}{l}\text { Processo de integração das áreas } \\
\text { meio não está finalizado; }\end{array}$ & $\begin{array}{l}\text { - Divisão da GELOG: GESAD e GESUP; } \\
\text { - Eliminar a área de Análise de Processos (alternativa 1). } \\
\text { - Fusão de GEFIN e GECONT criando a Gerência de Controladoria } \\
\text { (GECON). }\end{array}$ \\
$\begin{array}{l}\text { Necessidade de padronização de } \\
\text { melhores práticas dentro das áreas } \\
\text { meio; }\end{array}$ & $\begin{array}{l}\text { - Gerência de Operacionalização de Eventos subordinada à Coordenadoria } \\
\text { de Serviços Compartilhados (CSC). } \\
\text { - Condomínio subordinado à CSC. }\end{array}$ \\
\hline
\end{tabular}

Quadro 5 - Alternativas e propostas aprovadas do modelo organizacional e de gestão - consolidação da integração das áreas meio.

A proposta de implementação elaborada pela Consultoria $\mathrm{Z}$ foi dividida em três fases, garantindo foco nas mudanças prioritárias e distribuindo o potencial impacto na organização ao longo do período da MO. Logo, para implementar as alterações propostas, foi necessário estruturar frentes de trabalho para discutir e detalhar a implementação das mudanças. A Fase I proposta foi de 


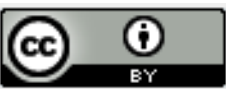

curto prazo, teve duração de um mês e realizou mudanças para o fortalecimento do Modelo de Gestão e de Governança (Figura 4).

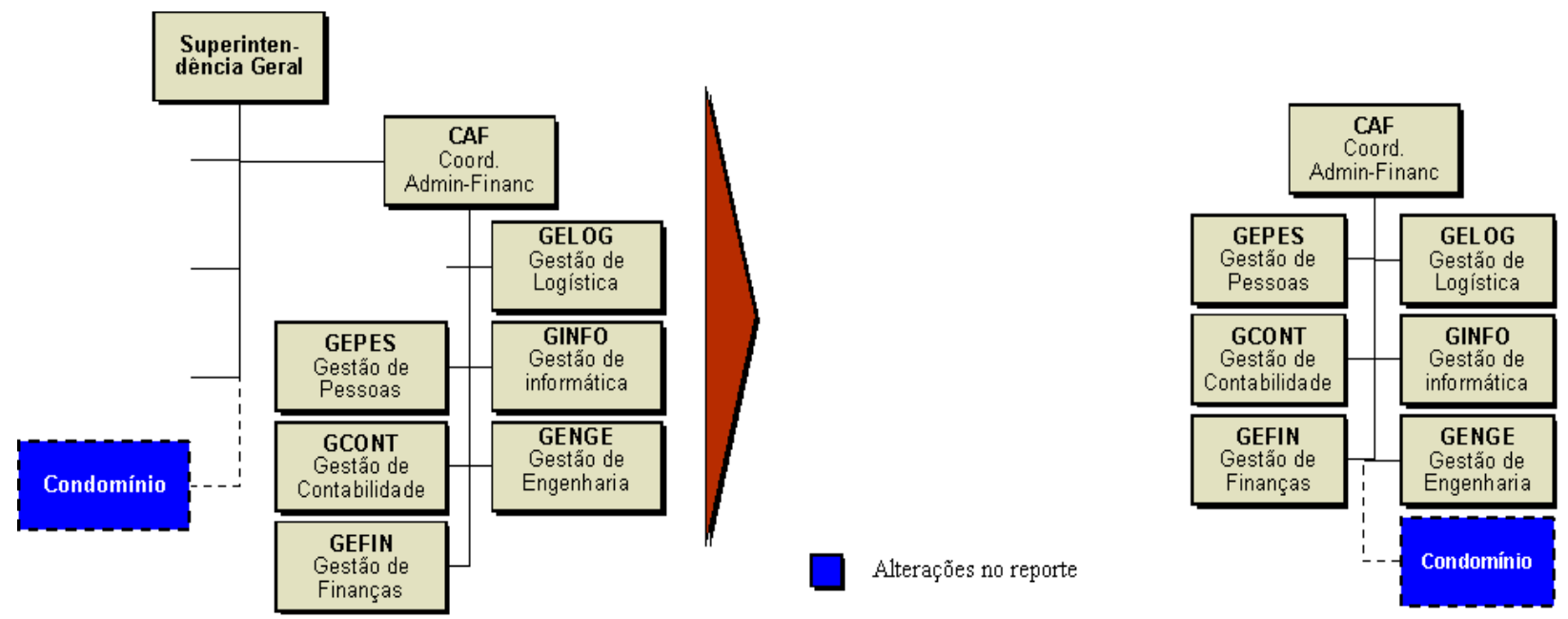

Figura 4 - Alterações organizacionais com a implementação da Fase I.

Fonte: Adaptado de Consultoria Z (2005).

As alterações organizacionais da Fase I foram implantadas de agosto a setembro de 2005, adotando o organograma Fase I (Figura 5). A Fase II realizou mudanças de maior impacto, com duração de quatro meses e consolidou a integração das áreas meio (coordenadoria de serviços compartilhados) - Figura 6.
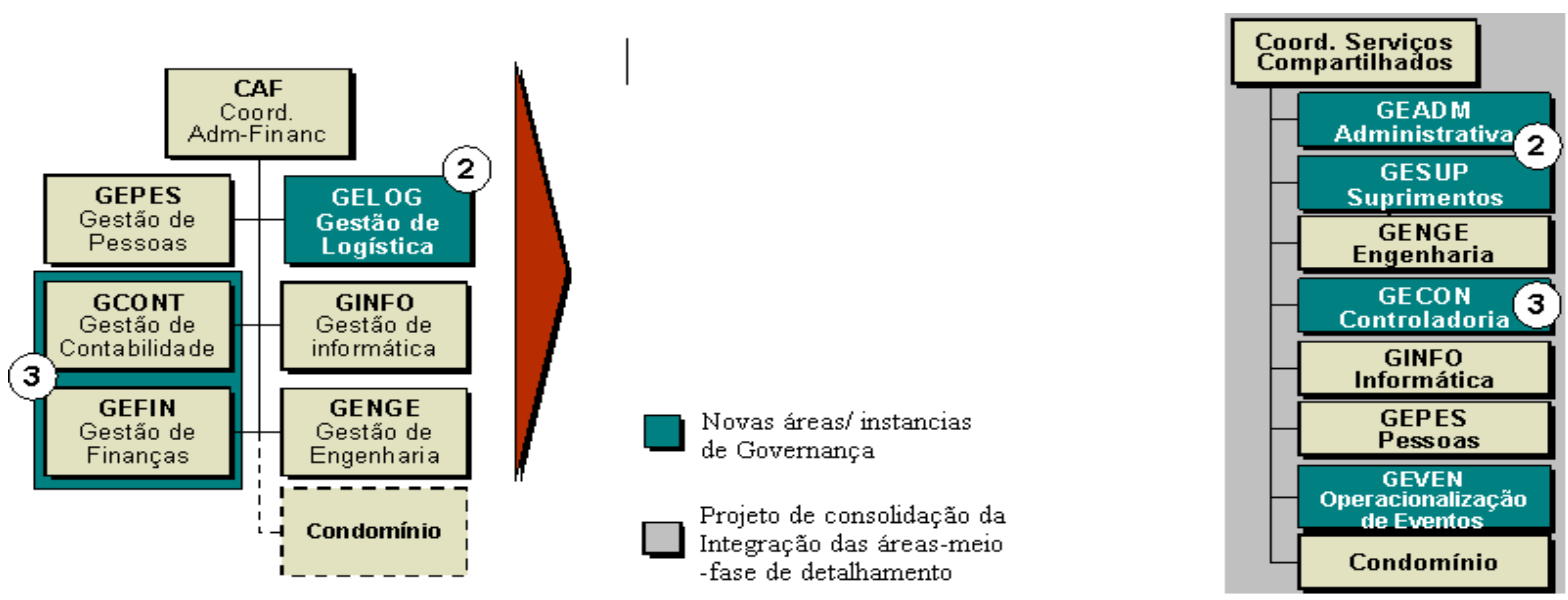

Figura 5 - Alterações organizacionais com a implementação da Fase II.

Fonte: Adaptado de Consultoria Z (2005). 


\section{Revista Produç@̃}

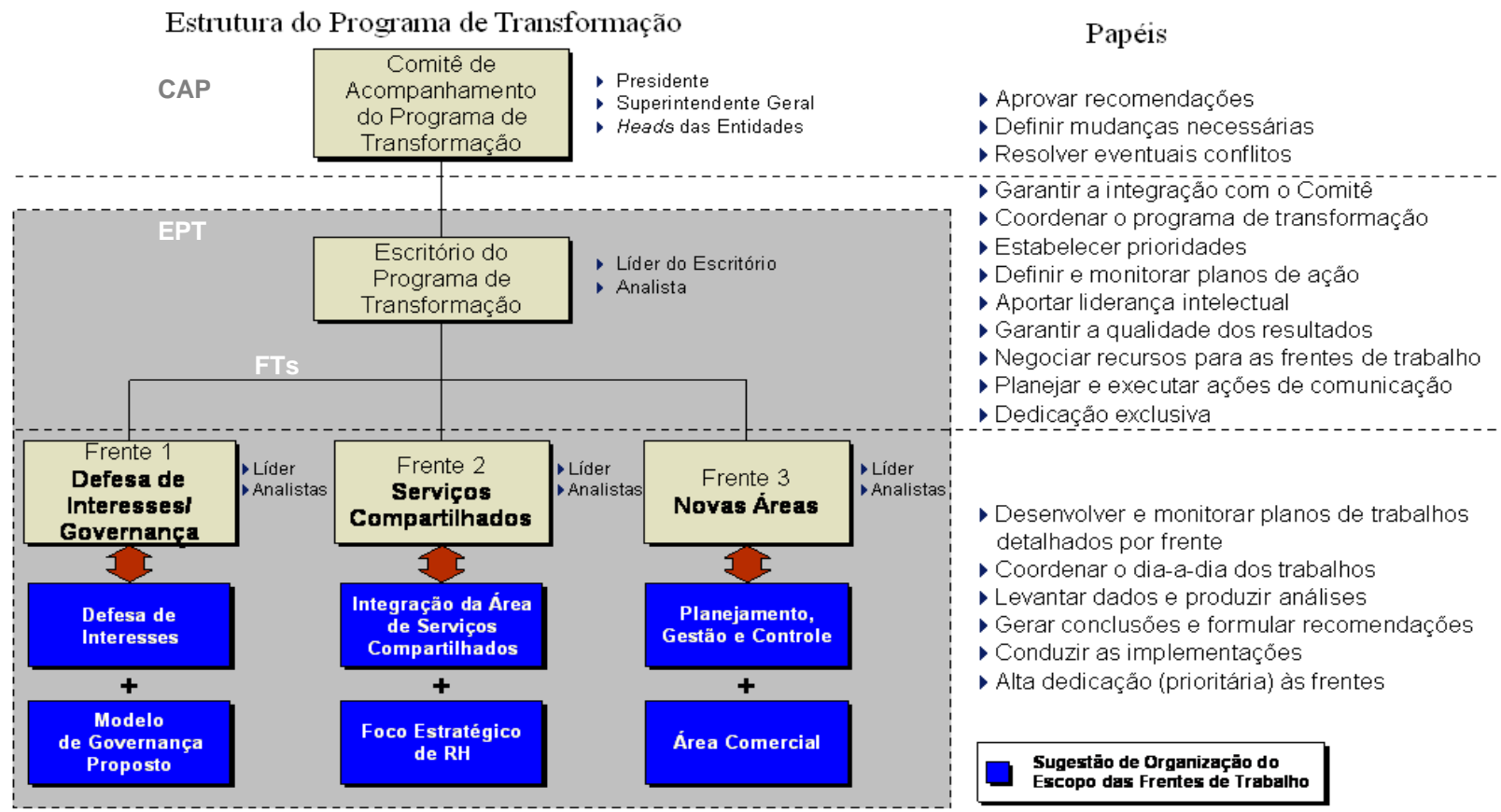

Figura 6 - Estrutura do Programa de Transformação.

Fonte: Consultoria Z (2005).

As alterações organizacionais propostas na Fase II foram realizadas no prazo estabelecido, de outubro/ 2005 a fevereiro/ 2006, adotando o organograma Fase II (Figura 6). A Fase III, para a consolidação da integração das áreas meio foi a etapa de implementar a consolidação dos Serviços Compartilhados. Os resultados da Fase III foram obtidos dentro do prazo, iniciando em março e finalizando em setembro/ 2006, porém as melhorias de processo dos serviços compartilhados tiveram continuidade até o presente ano. Para acompanhar os FCS e as alterações propostas, definiuse uma estrutura dedicada a realizar a gestão da MO (Figura 11), com diferentes instâncias para a tomada de decisão e as ações somente eram realizadas a partir da aprovação do CAPT.

\subsection{ANÁLISES APROFUNDADAS}

Nesta etapa foi descrito o processo de implementação das alterações propostas, focando no alcance da consolidação da integração das áreas meio do novo modelo de gestão e governança do Sistema FIERGS. Assim, descrevem-se as ações implementadas pelas Frentes de Trabalho (FT), Escritório do Programa de Transformação (EPT) e seus respectivos resultados. A implementação da MO na Entidade passou a chamar-se: Programa de Transformação do Sistema FIERGS. As FT utilizaram as sistemáticas $\mathrm{A}$ e $\mathrm{Z}$ para detalhar as propostas e submeter para a aprovação do Comitê de Acompanhamento do Programa de Transformação (CAPT). A origem destas sistemáticas e as unidades organizacionais de aplicação foram: Sistemática A - estruturada pelo EPT, para 


\section{Revista Produç@o}

Universidade Federal de Santa Catarina - UFSC

www.producaoonline.org.br

ISSN 1676 - 1901 / Vol. X/ Num.I/ 2010

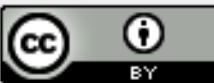

acompanhar e gerenciar a MO nas áreas: GEVEN (operacionalização de eventos) e GENGE; Sistemática $Z$ - propriedade da Consultoria $Z$ e aplicada pela mesma. Esta última utilizada em: GINFO; GESUP; GEPES GECON - Finanças e Contabilidade. A mesma Sistemática Z foi aplicada pelo EPT no Condomínio.

A estrutura da Sistemática A foi composta por ferramentas de apoio, que foram utilizadas para formalizar o trabalho desenvolvido pelas FT. Esse conjunto de ferramentas era composto por: diretrizes do Programa de Transformação; matriz de responsabilidades; aprovador de decisões; registro de reuniões; status de desenvolvimento de FT; alterações de escopo. A Sistemática Z detalhou as principais alternativas de melhoria, definindo os planos de ação para a implementação (Figura 7).

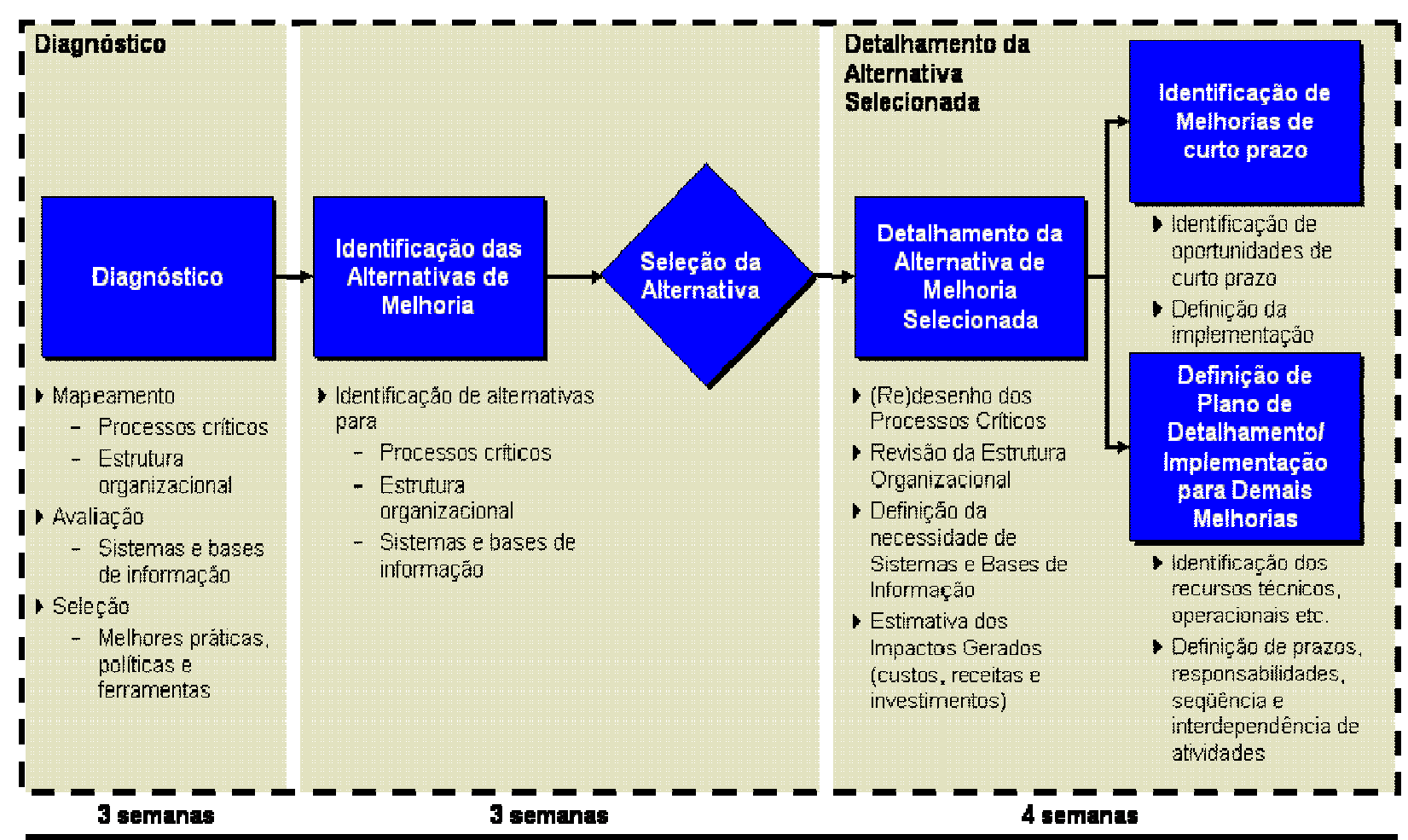

Figura 7 - Sistemática Z - Processo de detalhamento da MO.

Fonte: Consultoria Z (2005).

A implementação das propostas do Modelo Organizacional e de Gestão no Sistema FIERGS foi realizada na estruturação de FT, relacionados ao tópico de consolidação da integração das áreas meio, com os respectivos resultados identificados (Quadro 6). 


\begin{tabular}{|c|c|c|c|c|}
\hline $\begin{array}{c}\text { Frente de } \\
\text { Trabalho (FT) }\end{array}$ & $\begin{array}{c}\text { Atores } \\
\text { envolvidos }\end{array}$ & $\begin{array}{c}\text { Sistemática } \\
\text { utilizada }\end{array}$ & $\begin{array}{c}\text { Duração } \\
\text { FT }\end{array}$ & Resultados Alcançados \\
\hline $\begin{array}{c}\text { Engenharia - } \\
\text { GENGE }\end{array}$ & $\begin{array}{l}2 \text { técnicos EPT e } \\
4 \text { especialistas da } \\
\text { FIERGS }\end{array}$ & $\begin{array}{l}\text { Sistemática } \\
\text { A, aplicada } \\
\text { pelo EPT. }\end{array}$ & 3 meses & $\begin{array}{l}\text { Análise macro fluxo atual de demandas da } \\
\text { Engenharia; redesenho dos processos e } \\
\text { atividades; revisão, ajuste. }\end{array}$ \\
\hline $\begin{array}{l}\text { Eventos - } \\
\text { GEVEN }\end{array}$ & $\begin{array}{l}2 \text { técnicos EPT e } \\
4 \text { especialistas da } \\
\text { FIERGS. }\end{array}$ & $\begin{array}{l}\text { Sistemática } \\
\text { A, aplicada } \\
\text { pelo EPT. }\end{array}$ & 3 meses & $\begin{array}{l}\text { Mapeados fluxogramas dos processos de } \\
\text { Operacionalização de Eventos do CIERGS, SESI } \\
\text { e SENAI; formatação de checklist por tipo } \\
\text { evento. }\end{array}$ \\
\hline $\begin{array}{l}\text { Administração } \\
\text { - GESAD }\end{array}$ & $\begin{array}{l}3 \text { técnicos EPT e } \\
5 \text { especialistas da } \\
\text { FIERGS. }\end{array}$ & $\begin{array}{l}\text { Sistemática } \\
\mathrm{Z} \text {, aplicada } \\
\text { pelo EPT. }\end{array}$ & 3 meses & $\begin{array}{l}\text { Implantação sistema de viagens; software de } \\
\text { solicitação e gestão dos serviços e recursos de } \\
\text { transporte; estruturação políticas de viagens; } \\
\text { patrimônio; seguros. Sistema de código de barras } \\
\text { na expedição. }\end{array}$ \\
\hline $\begin{array}{c}\text { Suprimentos - } \\
\text { GESUP }\end{array}$ & $\begin{array}{l}1 \text { técnico EPT, } 1 \\
\text { técnico } \\
\text { Consultoria Z e } 9 \\
\text { especialistas da } \\
\text { FIERGS. } \\
\end{array}$ & $\begin{array}{l}\text { Sistemática } \\
\text { Z, aplicada } \\
\text { pela } \\
\text { Consultoria } \\
\text { Z. } \\
\end{array}$ & 3 meses & $\begin{array}{l}\text { Unificação do processo de compras; implantação } \\
\text { de sistema único e informatizado de compras; } \\
\text { unificação dos cadastros de fornecedores e de } \\
\text { produtos; terceirização dos almoxarifados. }\end{array}$ \\
\hline $\begin{array}{c}\text { Controladoria - } \\
\text { GECON }\end{array}$ & $\begin{array}{l}2 \text { técnicos do } \\
\text { EPT, } 1 \text { técnico } \\
\text { da Consultoria Z } \\
\text { e } 9 \text { especialistas } \\
\text { da FIERGS. }\end{array}$ & $\begin{array}{l}\text { Sistemática } \\
\text { Z, aplicada } \\
\text { pela } \\
\text { Consultoria } \\
\text { Z. }\end{array}$ & 3 meses & $\begin{array}{l}\text { Sistema SOGI; centralização das conciliações; } \\
\text { relatórios gerenciais até o } 7^{\circ} \text { dia útil; revisão e } \\
\text { automatização critérios de rateio; integração } \\
\text { entrada de NFs com Sistema Fiscal; sistema de } \\
\text { faturamento no contas a receber; centralização } \\
\text { do fluxo de caixa; contabilização automática da } \\
\text { arrecadação. }\end{array}$ \\
\hline $\begin{array}{l}\text { Tecnologia da } \\
\text { Informação - } \\
\text { GINFO }\end{array}$ & $\begin{array}{l}1 \text { técnico } \\
\text { Consultoria Z e } 4 \\
\text { especialistas da } \\
\text { FIERGS. }\end{array}$ & $\begin{array}{l}\text { Sistemática } \\
\text { Z, aplicada } \\
\text { pela } \\
\text { Consultoria } \\
\text { Z. }\end{array}$ & 3 meses & $\begin{array}{l}\text { Implantação de pacote integrado de soluções em } \\
\text { TI; terceirização do desenvolvimento de } \\
\text { projetos; telecom e energia; definição de } \\
\text { políticas e procedimentos que regulamentam as } \\
\text { ações de TI. }\end{array}$ \\
\hline $\begin{array}{l}\text { Recursos } \\
\text { Humanos - } \\
\text { GEPES }\end{array}$ & $\begin{array}{l}1 \text { técnico EPT, } 1 \\
\text { técnico } \\
\text { Consultoria } \mathrm{Z} \text { e } 7 \\
\text { especialistas da } \\
\text { FIERGS. }\end{array}$ & $\begin{array}{l}\text { Sistemática } \\
\text { Z, aplicada } \\
\text { pela } \\
\text { Consultoria } \\
\quad \text { Z. }\end{array}$ & 3 meses & $\begin{array}{l}\text { Plano de cargos unificado; adoção de } \\
\text { remuneração variável; integração de políticas de } \\
\text { provimento; descentralização de processos } \\
\text { seletivos; sistema de avaliação individual; } \\
\text { informatização ponto; implantação de projeto } \\
\text { para atualização anual do PPRA. }\end{array}$ \\
\hline
\end{tabular}

Quadro 6 - Implementação das FT do Modelo Organizacional e de gestão e as variáveis envolvidas - Consolidação da integração das áreas meio.

A partir dos resultados obtidos com as FT (Quadro 6), comparou-se com as deficiências identificadas, as alternativas propostas e as ações implementadas, consolidadas na matriz de 
consolidação da integração das áreas meio (Quadro 7).

\begin{tabular}{|c|c|c|}
\hline Deficiências & Proposta/ Alternativa Aprovada & Ações Implementadas \\
\hline $\begin{array}{c}\text { Processo de } \\
\text { integração das } \\
\text { áreas meio não está } \\
\text { finalizado }\end{array}$ & \multirow{2}{*}{$\begin{array}{l}\text { - Distribuição das atividades da GELOG: } \\
\text { - Descentralizar o Cadastro Corporativo. } \\
\text { - Eliminar a área de Análise de Processos. } \\
\text { - Fusão da GEFIN com GCONT criando a } \\
\text { Gerência de Controladoria (GECON). } \\
\text { • Criar a GEVEN subordinada à } \\
\text { Coordenadoria de Serviços Compartilhados; } \\
\text { - Condomínio subordinado à Coordenadoria } \\
\text { de Serviços Compartilhados. }\end{array}$} & \multirow{2}{*}{$\begin{array}{l}\text { - Atividades da GELOG distribuídas: } \\
\text { - Cadastro centralizado na GESUP - } \\
\text { alternativa } 1 \text { não foi implementada; } \\
\text { - Análise de processos integrada ao EPT - } \\
\text { alternativa } 1 \text { não foi implementada; } \\
\text { - Criada GECON, padronizados } \\
\text { processos e otimização dos recursos; } \\
\text { - Estruturação e criação da GEVEN; } \\
\text { - Subordinação do Condomínio à } \\
\quad \text { Superintendência Geral. }\end{array}$} \\
\hline $\begin{array}{c}\text { Necessidade } \\
\text { padronização de } \\
\text { melhores práticas } \\
\text { nas áreas meio }\end{array}$ & & \\
\hline
\end{tabular}

Quadro 7 - Matriz de comparação entre deficiências, alternativas aprovadas e ações implementadas FT Consolidação da integração das áreas meio.

\subsection{AVALIAÇÃO GERAL DO PROCESSO DE MO}

A avaliação geral do processo de MO consistiu em uma análise geral, em que são verificados os ganhos obtidos e as dificuldades enfrentadas. Essa avaliação foi realizada através da entrevista com o Presidente do Sistema FIERGS, representante da alta administração (CAPT), em fevereiro de 2008. Na entrevista, foram analisadas todas as etapas do processo de MO, as sistemáticas A e Z utilizadas e os FCS resultantes. Ainda, foi avaliada a inter-relação entre as sistemáticas e os FCS, através de uma matriz de correlação.

A primeira questão foi relativa aos aspectos referentes ao Sistema FIERGS que o levaram a realizar uma MO. O Presidente considera o Sistema FIERGS uma entidade de grande porte (aproximadamente 4.000 funcionários) e com produtos diversificados, que tem como clientes os setores industriais do Rio Grande do Sul. No entanto, preocupa-se com o alinhamento da cultura, valor, ganhos e entre outros aspectos das entidades que compõem o Sistema FIERGS. Entretanto, as constantes trocas de comando da entidade (mandatos com duração de três anos) influenciam a cultura organizacional e transmitem fragilidade, criando vícios que se enraízam à entidade. Visto isso, o Presidente crê na tendência das organizações atualizarem sua cultura e tradição, buscando continuamente modernizar-se, focando permanentemente na agilidade e flexibilidade do atendimento das demandas de clientes e mercado.

A segunda questão foi relativa aos principais ganhos organizacionais da entidade com a MO. O Presidente identificou ganhos organizacionais relacionados ao atendimento das problemáticas que levaram à iniciativa de MO, ressaltando a unificação das culturas organizacionais das entidades em uma única do Sistema FIERGS. Anteriormente à MO, essas culturas eram dissipadas e divergentes, devido à diversidade de produtos e serviços. 
As principais dificuldades enfrentadas na utilização das Sistemáticas de apoio A e Z foi a terceira questão indagada. Para o Presidente, uma das principais dificuldades relacionava-se à cultura organizacional, referente à sensibilização dos funcionários em crer no acontecimento das mudanças, resultados a serem obtidos e que a iniciativa de reestruturação não seria uma atitude de modismo. A MO proposta para a entidade estruturou e consolidou o modelo de gestão e de governança; desmistificou a crença na abundância financeira da entidade. Outra dificuldade em federações de indústrias é o fator político, que interfere nos posicionamentos técnicos e operacionais. A quarta questão foi relativa à priorização dos sete FCS em ordem crescente de importância e seus comentários relativos à ordem definida. Esta ordem é definida como: mudança cultural, descompasso por uma única cultura organizacional; comunicação constante e eficiente, pelas entidades carecerem de ações de uniformização da comunicação; alocação bem definida de papéis e responsabilidades, responsáveis por processos para cobrança por resultados; acompanhamento freqüente, avaliação de desenvolvimento e medição de resultados; disponibilização de recursos em quantidade e qualidade adequados, consultoria para manter o foco em resultados; gestão ativa e dedicada, implementação das ações e obtenção de resultados; objetivos e metas clarificados, consciência dos objetivos que a entidade deseja alcançar.

A quinta questão se referia à análise e validação da matriz de inter-relação (Quadro 8) entre as sistemáticas utilizadas e os FCS resultantes dessas aplicações, que são definidos em três tipos de impactos para a Entidade: positivo; indiferente; negativo. O Quadro 8 ilustra que a Sistemática Z, quando aplicada pela Consultoria Z, obteve o melhor desempenho dentre as demais.

\begin{tabular}{|c|c|c|c|}
\hline FCS & Sistemática A & $\begin{array}{c}\text { Sistemática Z - } \\
\text { Consultoria Z }\end{array}$ & Sistemática Z pelo EPT \\
\hline Gestão ativa e dedicada & Negativo & Positivo & Negativo \\
\hline Objetivos e metas clarificados & Negativo & Positivo \\
\hline $\begin{array}{c}\text { Acompanhamento freqüente } \\
\text { em quantidade e qualidade } \\
\text { adequados }\end{array}$ & Positivo & Positivo & Positivo \\
\hline $\begin{array}{c}\text { Disponibilizac̃o de recursos } \\
\text { Alocação bem definida de }\end{array}$ & Negativo & Positivo & Positivo \\
\hline $\begin{array}{c}\text { Comunicação constante e } \\
\text { eficiente }\end{array}$ & Negativo & Positivo & Negativo \\
\hline $\begin{array}{c}\text { Mudança cultural } \\
\text { Mapilidades }\end{array}$ & Negativo & Indiferente & Negativo \\
\hline
\end{tabular}




\section{Revista Produç@o}
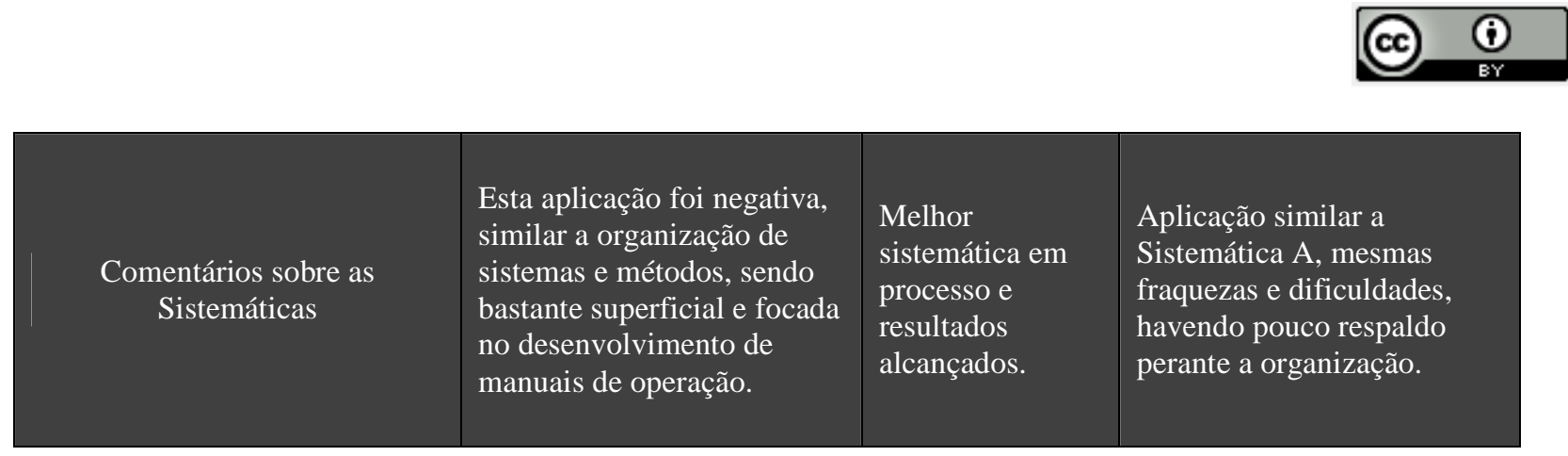

Quadro 8 - Matriz de inter-relação entre Sistemáticas A e Z e FCS validada.

A sexta e última questão foi relativa ao caso da MO no Sistema FIERGS, se poderia ser considerado de sucesso. $\mathrm{O}$ respondente crê na MO da entidade, que instaurada há cerca de três anos, trouxe significativas mudanças na cultura organizacional e aprimoramento de métodos de controle e de resultados. propor uma sistemática de apoio

\section{PROPOSTA DE UMA NOVA SISTEMÁTICA DE APOIO}

A partir das etapas precedentes a esta, é possível estruturar e propor uma sistemática de apoio para MO em entidades do tipo federações de indústrias e buscando a contribuição positiva dos fatores críticos de sucesso identificados.

Para iniciar a proposição da nova sistemática de apoio, denominada sistemática N, analisou-se a matriz de inter-relação (Quadro 8), validada pelo representante da alta administração entrevistado. Dentre as Sistemáticas A e Z utilizadas no estudo de caso e os sete FCS resultantes, constatou-se que a Sistemática $Z$ aplicada pela Consultoria $Z$ foi a que resultou na maior contribuição positiva dos impactos dos FCS na MO (Tabela 1). Além disso, os dois principais FCS enumerados na entrevista de validação geram impactos negativos em todas as sistemáticas aplicadas, exceto na Sistema Z aplicada pela Consultoria Z.

Sistemáticas de apoio à MO

\begin{tabular}{c|c|c|c}
\hline Impactos & Sistemática A & Sistemática Z pela Consultoria Z & Sistemática Z pelo EPT \\
\hline Negativos & 6 FCS $(86 \%)$ & 1 FCS $(14 \%)$ & 4 FCS $(57 \%)$ \\
\hline Positivos & 1 FCS $(14 \%)$ & 5 FCS $(72 \%)$ & 3 FCS $(43 \%)$ \\
\hline Indiferentes & 0 FCS $(0 \%)$ & 1 FCS $(14 \%)$ & 0 FCS $(0 \%)$ \\
\hline
\end{tabular}

Tabela 1 - Avaliação dos impactos dos FCS nas Sistemáticas de apoio.

Baseando-se no Quadro 8 e na Tabela 1, notou-se que a utilização da Sistemática Z (Figura 7) resultou em diferentes FCS, dependendo de quem as implementou (seja EPT ou Consultoria Z) constituindo, assim, um fator fundamental na obtenção dos resultados almejados. A partir disto, a diferença entre os resultados dos FCS gerados, positivamente pela Consultoria Z e indiferentes/ 


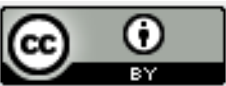

negativos pelo EPT, foi dada pela ausência de determinadas características neste último. Buscou-se então suprimir tais características através da estruturação da Sistemática N, que está dividida em quatro macros processos de realização (Figura 8).

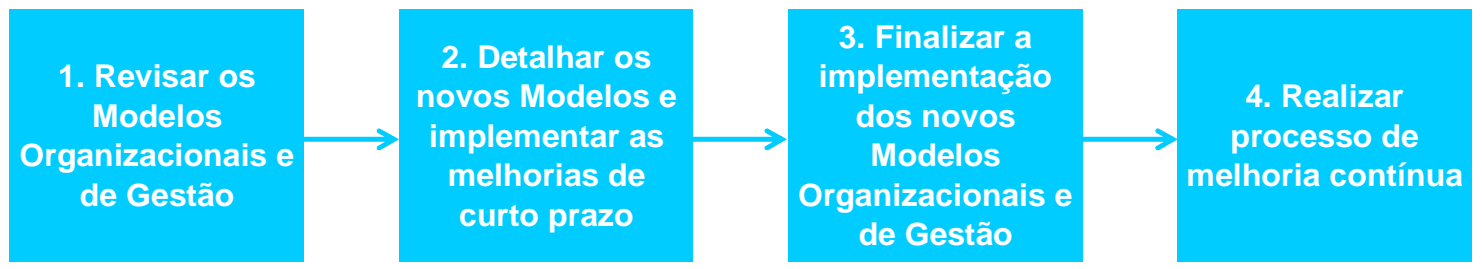

Figura 8 - Macro processos de realização da MO.

A Sistemática $\mathrm{N}$ é proposição de sistemática de apoio para $\mathrm{MO}$ em entidades do tipo federações de indústrias, buscando a contribuição positiva dos FCS, calcando-se na Sistemática Z. Os quatro macros processos de realização de MO (Figura 8) da Sistemática N desdobraram-se em onze etapas de desenvolvimento e uma etapa permanente (Figura 9).

Para melhor compreensão da Sistemática N, são descritas as etapas que a compõem, os FCS que devem contribuir positivamente, a procedência na literatura das contribuições (Figura 10), além da relevância destas etapas em uma sistemática de apoio à MO.

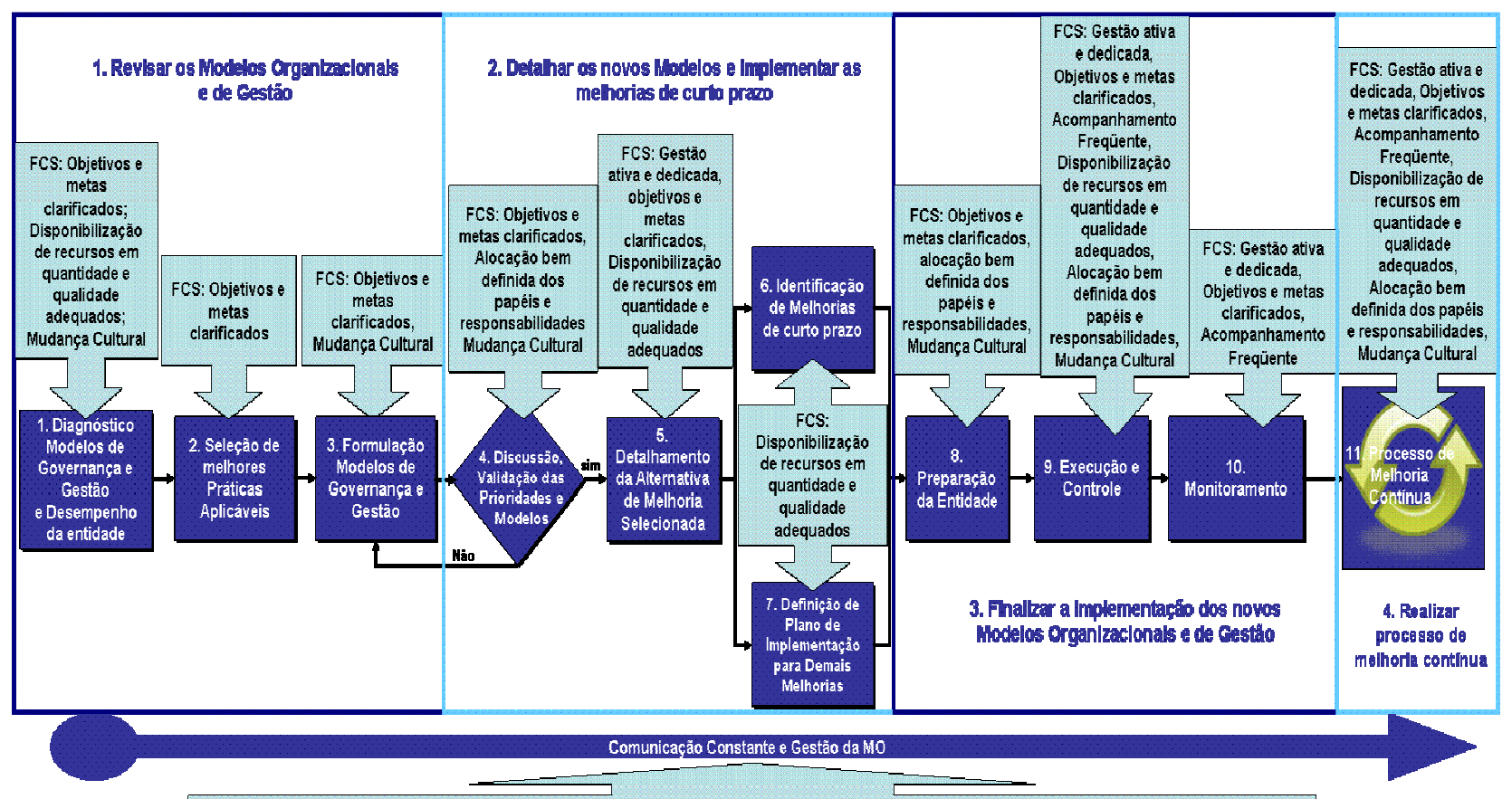

FCS: Objetivos e metas clarificados, Acompanhamento Freqüente, Disponibilização de recursos em quantidade e qualidade adequados, Mudança Cultural

Figura 9 - Sistemática $\mathrm{N}$ - etapas de um processo de MO. 


\section{Revista Pr.tuç@o}

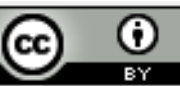

\begin{tabular}{|c|c|c|c|c|c|c|c|c|c|c|c|c|}
\hline & \multicolumn{12}{|c|}{ Etapas de um processo de MO } \\
\hline & $\begin{array}{l}\text { Comunicacão } \\
\text { constante } \\
\text { gestã da MO }\end{array}$ & $\begin{array}{l}\text { 1. diagnósticico } \\
\text { Modelos de } \\
\text { Governança } \\
\text { Gestae } \\
\text { desempenhhe }\end{array}$ & $\begin{array}{l}\text { 2. seleceãa } \\
\text { melhores } \\
\text { prrácicas } \\
\text { aplicáveis }\end{array}$ & $\begin{array}{l}\text { 3. formulacãõo } \\
\text { Modelos de } \\
\text { Governança e } \\
\text { Gestão }\end{array}$ & $\begin{array}{l}\text { 4. discussaio } \\
\text { validacáo } \\
\text { prioidadese } \\
\text { modelos }\end{array}$ & $\begin{array}{l}5 . \\
\text { detalhamento } \\
\text { alternativa de } \\
\text { melloria } \\
\text { selecionada }\end{array}$ & $\begin{array}{l}\quad 6 . \\
\text { identificaão } \\
\text { melhorias de } \\
\text { curto prazo }\end{array}$ & $\begin{array}{l}\text { 7. definicãa } \\
\text { plano dea } \\
\text { implementac } \\
\text { ao opara } \\
\text { demais }\end{array}$ & $\begin{array}{l}\text { 8. preparacão } \\
\text { da entidade }\end{array}$ & $\begin{array}{l}\text { 9. execuçăo, } \\
\text { e controle }\end{array}$ & $\begin{array}{l}10 . \\
\text { onitoram } \\
\text { ento }\end{array}$ & 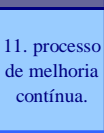 \\
\hline Azevedo (1999) & & & & & & & & & & & & \\
\hline Azevedo (2007) & & & & & & & & & & & & \\
\hline Azambuja (2003) & & & & & & & & & & & & \\
\hline Baldi (1999) & & & & & & & & & & & & \\
\hline Consultoria E & & & & & & & & & & & & \\
\hline Consultoria Z & & & & & & & & & & & & \\
\hline Duck (1993) & & & & & & & & & & & & \\
\hline EPT & & & & & & & & & & & & \\
\hline Kanter (1992) & & & & & & & & & & & & \\
\hline $\begin{array}{l}\text { Kettinger (1997) } \\
\text { apud Torres (2002) }\end{array}$ & & & & & & & & & & & & \\
\hline Kotter (1995) & & & & & & & & & & & & \\
\hline $\begin{array}{l}\text { Larkin; Larkin } \\
\text { (1909) }\end{array}$ & & & & & & & & & & & & \\
\hline $\begin{array}{l}\text { Lorange et al. } \\
\text { (1994) }\end{array}$ & & & & & & & & & & & & \\
\hline Mandelli (2000) & & & & & & & & & & & & \\
\hline Motta (1998) & & & & & & & & & & & & \\
\hline Obolensky (1994) & & & & & & & & & & & & \\
\hline $\begin{array}{l}\text { Pascale; Sternin } \\
\text { (2005) }\end{array}$ & & & & & & & & & & & & \\
\hline $\begin{array}{c}\text { Rodrigues e } \\
\text { Nakayama (2000) }\end{array}$ & & & & & & & & & & & & \\
\hline
\end{tabular}

Figura 10 - Contribuições de autores e caso prático na proposição da Sistemática N.

A comunicação constante e a gestão da MO devem perdurar por todo o processo de MO da Sistemática N (Figura 9), sendo fundamental envolver os funcionários em uma comunicação aberta e franca, através de canais formais e informais (AZEVEDO, 2007), comunicando fatos e não valores organizacionais (LARKIN; LARKIN, 1996). Para realizar a gestão efetiva, deve haver um grupo que discuta os assuntos estratégicos, envolvendo-se com os planos e resultados em médio e longo prazo e as problemáticas operacionais do cotidiano (AZEVEDO, 1999). Ignorar a necessidade de gerir e comunicar gera impactos negativos de FCS: resistência e falta de envolvimento dos funcionários; atraso no cronograma; falta de visão estratégica; subutilização de recursos organizacionais.

A primeira etapa da Sistemática N (Figura 10) compreende a avaliação dos desempenhos financeiro, operacional, de gestão e a estrutura organizacional, sendo esta a etapa impulsionadora da MO, que identifica problemáticas organizacionais e dimensionam ganhos, flexibilidade e crescimento organizacional (KANTER et al., 1992). Ignorar a importância de realizar o diagnóstico dos Modelos de Governança e Gestão e desempenho seria iniciar a MO desconhecendo seus reais problemas, gerando os impactos negativos de FCS: desperdício de recursos; alterações 
organizacionais sem propósito estabelecido e/ ou fundamentado; dificuldade de sensibilizar e/ ou envolver os funcionários.

Na segunda etapa da sistemática é realizada a identificação das melhores práticas aplicáveis nos modelos, em que estas devem ser utilizadas como estímulo ao conhecimento (PASCALE; STERNIN, 2005), considerando particularidades organizacionais. Desconsiderar a seleção de melhores práticas seria ignorar os comparativos práticos e os reflexos das propostas na organização, que poderia resultar na ocorrência da falta de clareza dos resultados esperados.

Para a terceira etapa da Sistemática $\mathrm{N}$ é tratada a definição de princípios e critérios, para a escolha dentre as alternativas que compreendem o novo modelo organizacional. Isto, visando extinguir as lacunas, duplicações e áreas de conflito da estrutura organizacional, sendo desenvolvidas por uma equipe da MO (MOTTA, 1998). Neste contexto, a ausência da formulação do Modelo de Governança e de Gestão na MO resulta em impactos negativos de FCS: inconsistência dos resultados propostos; desconhecimento dos resultados esperados pelos funcionários.

Já, na quarta etapa, que é realizada pela alta administração, são selecionadas as alternativas que compreendem o novo modelo de Governança e de Gestão da entidade, devendo ser concisa, lógica (AZEVEDO, 1997) e, validada pela alta administração (MOTTA, 1998). A ausência da discussão e validação das prioridades e modelos gera reflexos negativos de FCS: indefinição de objetivos e metas esperados; inexistência de envolvimento e comprometimento da alta administração; permissão de ausência aos resistentes à iniciativa.

A quinta etapa compreende a estruturação de cronograma de atividades, estabelecendo vínculos entre atividades precedentes, indicadores de desempenho e o plano de recursos necessários para execução da MO. Ignorar o detalhamento das alternativas selecionadas resultaria em impactos negativos de FCS, como a impossibilidade de prever e antecipar problemas futuros; conhecer as expectativas em relação às atividades e seus resultados; planejar o cronograma financeiro, evitando interrupções e a desmistificação da MO para os funcionários.

A sexta e sétima etapas da Sistemática $\mathrm{N}$ trata da definição do plano de implementação curto, médio e longo prazo, juntamente com seus respectivos recursos, prazos, responsabilidades, seqüência de atividades, em que a gestão da MO é dada pela inter-relação e o balanceamento destas variáveis (DUCK, 1993). A inexistência da identificação de melhorias de curto prazo e definição do plano de implementação para as demais melhorias resultariam impactos negativos de FCS sob a ingestão sobre os recursos, acarretando na interrupção de atividades ou fim da iniciativa de MO.

$\mathrm{Na}$ oitava etapa da referida sistemática especifica-se a preparação da entidade para a MO, dada pela alta administração, que busca a sensibilização de funcionários através da disseminação dos benefícios para envolvidos, ressaltando que uma MO exige interação, cooperação e apoio (MOTTA, 1998). Ignorar esta preparação da entidade poderia resultar em impactos negativos de FCS: falta de comunicação de alterações que afetam rotinas de trabalho; desconhecimento da importância de participação dos funcionários; ausência da contribuição dos funcionários nos objetivos propostos; ações de mudança acontecendo sem controle.

A nona etapa da sistemática é a realização das propostas estruturadas nas fases anteriores. Esta, sendo dividida em: gestão da qualidade, pela auditoria nos processos e produtos para verificar sua eficiência; controle de alterações, pelo gerenciamento do escopo, custos e prazos da MO; 
administração da MO, através da gestão de recursos, logística e suporte administrativo (AZEVEDO, 1997). A inexistência da execução e/ ou controle implicaria em impactos negativos de FCS: ações sem ordem de realização; desconhecimento dos resultados alcançados; ausência de responsabilidade dos funcionários nas alterações; indisponibilidade de recursos; ausência de ações corretivas necessárias para ajuste ás propostas.

A décima etapa da Sistemática N constitui-se do acompanhamento da implementação das propostas estruturadas e seus reflexos organizacionais, dado os ajustes necessários durante a MO (AZAMBUJA, 2003), através do acompanhamento do progresso, monitoramento do alcance de metas, gestão de questões críticas e de risco. Desconsiderar o monitoramento da MO acarreta em impactos negativos de FCS: desconhecimento dos resultados alcançados e se os mesmos são satisfatórios ou insatisfatórios em relação aos objetivos propostos; gestão das questões críticas para que não interfiram nos ganhos propostos.

Finalmente, a décima primeira etapa aborda a consequiência da absorção dos novos valores na entidade. Assim, para este processo perdurar, a organização necessita de profundas e periódicas revisões em sua estrutura organizacional e no modelo de atuação (MANDELLI, 2003). Ignorar o processo de melhoria continua poderia gerar impactos negativos de FCS: ausência da avaliação organizacional constantemente; falta de demandas por novos e audaciosos objetivos e metas; perda do foco de atuação; falta de fôlego financeiro para continuamente investir na melhoria organizacional, ausência de mensuração de resultados; falta de responsabilidade no alcance das melhorias.

\section{CONSIDERAÇÕES FINAIS}

No que tange ao estudo de MO e a contribuição positiva dos FCS para organizações do tipo de Federação de Indústrias, estruturou-se a compreensão de uma mudança organizacional através do Programa de Transformação do Sistema FIERGS, em que foram levantados, identificados e registrados os procedimentos, ações realizadas e resultados obtidos no desenvolvimento do processo de reestruturação organizacional proposto para estudo de caso. A partir destas informações, realizou-se a descrição das sistemáticas de apoio utilizadas na $\mathrm{MO}$, seguido da análise e da comparação destas sistemáticas entre si, baseando-se nos FCS resultantes de suas aplicações.

Após analisar essas ferramentas de apoio, verificou-se a incidência de diferentes FCS no processo, variando conforme a sistemática de apoio utilizada, ou mesmo o ente que a utilizou. $\mathrm{O}$ resultado destas análises foi insumo para a estruturação e proposição de uma sistemática de apoio para MOs em organizações do tipo federação de indústrias, em que se priorizou a busca pela contribuição positiva dos FCS, respeitando suas características organizacionais. A partir das análises mencionadas, estruturou e propôs-se uma sistemática de apoio - denominada Sistemática N - na complexidade de uma entidade representante de um segmento federativo.

O período do estudo de caso registrado neste trabalho permitiu verificar que o impacto dos FCS, interferindo de maneira positiva ou negativa no resultado da mudança organizacional, foi a grande problemática resultante. E, buscando os resultados benéficos da MO para a Entidade do tipo Federação de Indústrias, estruturou-se a Sistemática N. O Sistema FIERGS permanece em fase de 
mudança organizacional, buscando alcançar ganhos organizacionais dados como fundamentais pela alta administração como, por exemplo, a integração dos processos de serviços compartilhados.

Finalizando este trabalho, é importante frisar que a complexidade dos assuntos MO e FCS permite interpor algumas considerações ainda presentes no tema abordado. Estes podem ser explicitados como proposição de trabalhos futuros, podendo-se incluir itens como: a ampliação do registro de conteúdo sobre sistemáticas de apoio, suas aplicações e resultados; análise e comparação dos resultados da implementação da Sistemática N; acompanhamento de casos práticos de mudança organizacional em outras entidades, como Federações de Indústria, Comércio, Agricultura e Sindicatos Patronais.

\section{REFERENCIAS}

AZAMBUJA, R. A mudança organizacional apoiada pelo planejamento estratégico: um estudo de caso no SESI-RS. Porto Alegre: PUCRS, 2003. Dissertação de Mestrado, Faculdade de Administração de Empresas, Pontifícia Universidade Católica do Rio Grande do Sul, 2003.

AZEVEDO, KPMG. Mudando para melhor: as melhores práticas para transformar sua empresa. São Paulo, SP: Atlas, 1997.

BRESSAN, F. O método do estudo de caso. Disponível em: <http://www.fecap.br/adm_online/art11/flavio.htm>. Acesso em: 21 Ago. 2007.

DUCK, J. D. Managing Change: The Art of Balancing. Harvard Business Review, USA, nov./ dez. 1993.

GARVIN, D. A.; ROBERTO, M. A. Change Through Persuasion. Harvard Business Review, USA, v. 83(2), 2005.

GONÇALVES, J. E. L. As empresas são grandes coleções de processos. RAE, São Paulo, v.40, n.1, p. 6-19, jan./ mar. 2000.

KANTER, R. M.; STEIN, B. A.; JICK, T. D. The challenge of organizational change: How companies experinse it and leaders guid it. NY, USA: The Free Press, 1992.

KERZNER, H. Gestão de Projetos: As Melhores Práticas. Porto Alegre: Bookman, 2002.

KOTTER, J. P. Leading Change: Why Transformation Efforts Fail. Harvard Business Review, USA, mar./ abr. 1995.

LARKIN, T. J.; LARKIN, S. Reaching and Changing Frontline Employees. Harvard Business Review, USA, mai./ jun. 1996.

LIMA, S. M. V. Mudança Organizacional: Teoria e Gestão. São Paulo: FGV, 2003.

LORANGE, P. et. al. Implementing strategic process: change, learning and co-operation. 1994.

MANDELLI, Consultores Associados. A disciplina e a arte da gestão das mudanças nas organizações: como integrar estratégias e pessoas. Rio de Janeiro: Elsevier, 2003. 
MOTTA, P. R. Transformação organizacional: a teoria e a prática de inovar. Rio de Janeiro: Qualitymark, 1998.

OBOLENSKY, N. Guia Prático de Reengenharia: técnicas e ferramentas para alcançar a mudança eficaz. São Paulo: Record, 1994.

PASCALE, R. T.; STERNIN, J. Your Company's Secret Change Agents. Harvard Business Review, USA, v. mai, p. 73-81, 2005.

RODRIGUES, A.; NAKAYAMA, M. K. Modelos de mudança em administração de empresas. Porto Alegre: EdiPUCRS, 2000.

SENGE, P. A dança das mudanças: os desafios de manter o crescimento e o sucesso em organizações. Rio de Janeiro: Campus, 2000.

TORRES, J. B. Um modelo dinâmico de apoio a gestão organizacional baseado na modelagem de processos utilizando componentes de software. Florianópolis: UFSC, 2002. Tese de Doutorado, Programa de Pós-Graduação em Engenharia de Produção, Universidade Federal de Santa Catarina, 2002.

YIN, R. K. Case study research: design and methods. 2 ed. London, Applied social research methods series, SAGE Publications, v.5, 1994. 